\title{
33. Tienodictyon zonatum, a New Stromatoporoid from Eastern Yunnan, China.
}

\author{
By Hisakatsu Yabe and Toshio Sugryama. \\ (Comm. by H. YABE, M.I.A., May 12, 1941.)
}

Recently the writers discovered a splendid specimen of an interesting stromatoporoid which now forms the subject of this short note, in an early collection of Chinese fossils stored in the Institute of Geology and Palaeontology, Tôhoku Imperial University ; it bears a label denoting "Loc. : Nanshan, Paichiaying, Yunnan"," but without mention of its geological horizon; this locality lies in Chienshui-hsien". Fortunately it has in association several slender columns of Amphipora, which are probably assignable to the well known species, $A$. ramosa Phillips characterizing the Middle Devonian. This species has a wide distribution in Europe, and is especially rich in Germany and the British Isles, and also occurs in China, the first record of its occurrence being made by the senior author from the Middle Devonian of Kueilin, Kuangsi ${ }^{3)}$; it seems to be a common fossil of Devonian limestones of Yunnan and Kuangsi. The Devonian and perhaps Middle Devonian age of the stromatoporoid dealt with below is therefore almost certain.

The stromatoporoid in question represents a new type as will be seen from the following description.

Tienodictyon zonatum, gn. et sp. nov.

Figs. 1-6

Coenosteum massive, some $14 \mathrm{~cm}$ broad, with a broad base of attachment and a convex upper surface; minutely granulated on upper surface, and distinctly thin-banded on weathered lateral surface. Epitheca unknown. Growth contiguous, contrary to the superficial banding. Canals like those of astrorhizae present here and there in coenosteum, better visible in vertical section than in tangential, usually simple and somewhat flexuous, $1 \mathrm{~mm}$ broad on an average and up to $5 \mathrm{~mm}$ long. Mamelon absent.

Under the microscope: thin-banded, though thoroughly continuous in structure, bands or laminae 1-1.5 mm thick, parallel and gently undulated. Outer layer or lamella thin, $0.15-0.25 \mathrm{~mm}$ thick, appearing as a continuous plate in thick slices, but consisting in reality of vertical trabeculae which are densely crowded and laterally almost contiguous as well exposed in sufficiently thin slices ; trabeculae mostly very short, but some elongated and extending downward into interlamellar space; interspaces between trabeculae (? perforation of lamella) rare, as broad as $0.25 \mathrm{~mm}$. Interlamellar space $0.8-1 \mathrm{~mm}$ thick, indistinctly divided
1) 雲南白像管南山:
2) 建水縣.
3) 廣西桂林. 

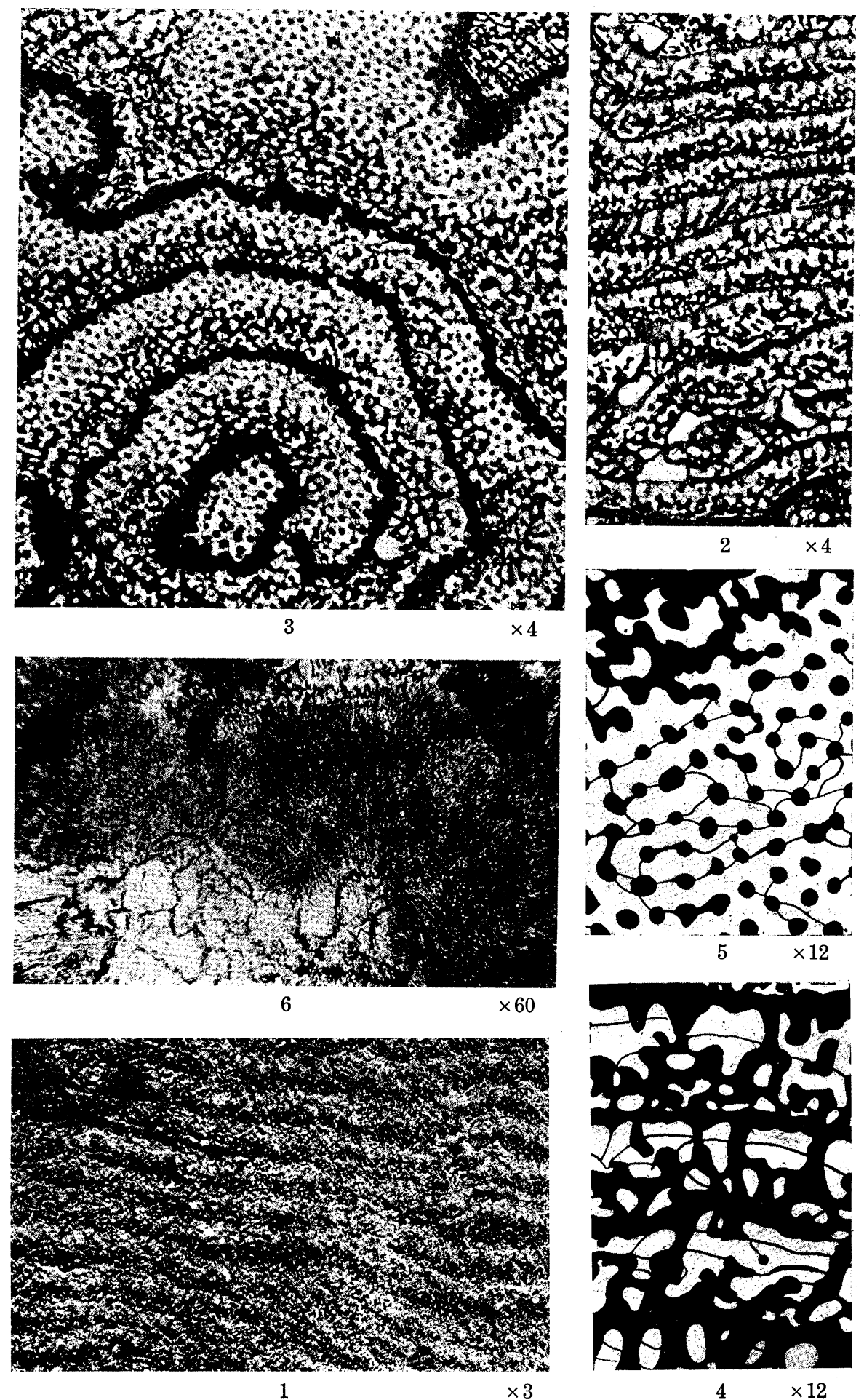

Tienodictyon zonatum, gen. et sp. nov. Reg. No. 65229 .

1. A part of weathered surface. 2, 4. Vertical section.

3 , 5. Tangential section. 6. A part of concentric layer. 
into two, upper and lower, parts by an undulated boundary; upper part with distant, irregularly spaced, more or less vertical trabeculae prolonged from lamella, variable in length and intervened by wide lacunae of variable sizes; lacunae, especially larger ones crossed more or less horizontally by very thin tabulae arranged usually on common levels and often convex upward; lower part occupied by vermiculate trabeculae of the same nature and of almost the same breadth with those of the upper part and partly prolonged from them; interspaces between trabeculae in the lower part provided rarely with tabulae. All trabeculae radially fibrous, without exhibiting any other structure. Locality: Nanshan, Paichiaying, Chienhsui-hsien, Eastern Yunnan, China. Reg. No. 65229.

Geological formation: Devonian (probably Middle Devonian).

Remarks: This fossil is very peculiar in several respects. It is thin-banded, these bands or laminae are much thinner than the "Latilaminae" which prevail in many forms of the Stromatoporoidea and thicker than "laminae" of most Clathrodictyon and similar forms; on the other hand, the thickness of the bands is of nearly the same magnitude with that of certain forms of the Sphaeractinoidea such as Circoporella, Plassenia and Sphaeractinia. In cursory observation the concentric lamellae which make the outer border of the bands appear to be a compact plate similar to those of the Sphaeractinoid genera. However, in bringing a sufficiently thin section under the microscope, the apparently compact lamellae soon resolve to an aggregate of numerous, mostly very short vertical trabeculae in close lateral contact, with their interspaces rarely left hollow; this characteristic feature hinders the inclusion of this fossil in the Sphaeractinoidea and brings it near to the Stromatoporoidea, especially to Clathrodictyon.

The interlamellar space of this fossil is vermiculated in its lower part composed of flexuous trabeculae as in the typical forms of Stromatopora s. s., though different from them in simply radial-fibrous microstructure of the trabeculae. In tangential section, the upper part of the interlamellar space exhibits numerous round dots, the cut ends of vertical trabeculae, quite free from one another, as seen in a similar section cut through the interlamellar space of Clathrodictyon, with which it also agrees well in the microstructure of trabeculae and of lamellae mentioned above. In its growth-mode, namely in alternating zone of rectilinear trabeculae and zone of vermicular, it reminds one of Milleporidium and also somewhat of Ludictyon; such a similar growthmode, however, gives no indication on their affinity.

As to the systematic position of this fossil it is at least certain that it represents a new genus which stands nearer to the Clathrodictyonidae than to the Stromatoporiidae; probably it may represent a distinct family in itself. 